\title{
Psychological Acceptance of Children with Develop-mental Disorders
}

\author{
Kasomo Daniel \\ Department of Religion, Theology, and Philosophy in Maseno University in Kenya \& Faculty of Psychology, St. James the Elder Theo- \\ logical Seminary, Jacksonville, Florida, USA
}

\begin{abstract}
On account of different kinds of impairment, a number of children often remain isolated from the normal course of personal and social development various types of family and community beliefs, attitudes and misconceptions, unequal and unfair treatments in family and partiality in behavior may often cause hardships for children with special needs. Negligence on the part of both government and society may play a significant role in demoting social inclusion of such children. The family members may often encounter a variety of problems in catering for the needs of children having some sorts of developmental disorders. To deal with these problems, they may require proper education and training. In this paper, the authors highlight the policy of the government of Kenya regarding social inclusion of children with special needs and specify the role of the family in the promotion of social inclusion through making use of various sources of support available.
\end{abstract}

Keywords Attitudes, Beliefs, Child, Needs, Special

\section{Introduction}

The Term: children with special needs" refers to children who have specific academic, behavioural, or physical needs, which cannot adequately be met in a regular classroom. It may include children with disabilities, having serious health problems and behavioural disorders. Gifted children are also considered as belonging to this category due to their higher order needs. According to Julka (2002: 48) the term also refers to children with situational disadvantages due to various catastrophes, among others. Malhotra (2002:23) asserts that children with special needs have to fight tough battles as they lack conditions, rights and opportunities easily available to their unencumbered counterparts. These children require appropriate infrastructure and environment at various levels, which can help them attain a holistic education and ensure their recognition as independent individuals with unique strengths and weaknesses. Mohey and Woodhouse (2002:7) identify the use of space, availability of equipment and of qualified people as important features of an appropriate social environment for such children.

The term "social inclusion" refers to the provision of appropriate opportunity for children with special needs to participate in all educational and social activities fully and equally with others (Goel, 2003: 100). Social inclusion lays

* Corresponding author:

dkasomo@hotmail.com (Kasomo Daniel)

Published online at http://journal.sapub.org/edu

Copyright (C) 2012 Scientific \& Academic Publishing. All Rights Reserved the foundation for an inclusive society, one in which all people belong at all times and where being "different" is accepted. Social inclusion prepares the society to receive them. On the other hand, inclusive education is an education which is non - discriminatory in terms of disability, culture, gender or other aspects of life and as assigned significance by a society (Abosi, 2006). It extends to all students in a community, with no exception and irrespective of their intellectual, physical, sensory or other abilities, while considering their equal rights to access the culturally valued curriculum of their society as full - time members of the age appropriate mainstream classroom. Inclusion emphasizes diversity over assimilation. To describe situations referring to the departure from social inclusion, terms such as social segregation, social isolation, marginalization and social vulnerability are commonly being used. These terms signify circumstances where participation of certain social groups or people in social, cultural, economic, educational and political processes is limited or is of segregated nature. Social exclusion takes place when human beings are stigmatized and put within narrow pathologised boundaries. The disabled or persons with special needs tend to be losers in a situation that is divided between those who are able or normal and those who are unable and disabled and considered as abnormal (Alur, 2002:21).

Social inclusion is linked to the availability of means to provide social justice to children with special needs and presupposes the creation of an open, just and undivided society, a society where everyone would be able to enjoy equal rights, freedoms, and social services, such as education, 
health care, housing, employment, etc. The process of social inclusion requires focusing on a system which is ready to embrace everyone. For children with special needs, it means a shift in services from care to education and personal development.

According to Goel (2002: 104) there is a range of national and international documents advocating for the principles of inclusion, such as the Convention of the Rights of the Child (CRC) of 1989, World Conference on Education For All (EFA) held at Jomtien, 1990, and the Salamanca Statement of Spain, 1994. But the achievement of the goal of social inclusion is faced with many challenges related to rapid social change, increasing material inequality, high rates of unemployment and negative outcomes of the process of globalization.

Nevertheless, it is imperative to achieve this goal. One of the ways to facilitate the social inclusion of children with special needs is to ensure greater involvement of the family members of such children, i.e. individuals who are ready to come up with their personal initiatives rather than rely exclusively on professional consultancies and services.

Members of families of such children are expected to be prepared especially psychologically to face the numerous challenges regarding:

a. Learning to implement specialized care routines;

b. Meeting appointments for frequent consultations;

c. Spending significant amounts of time, money and energy to get appropriate services as and when required;

d. Being excluded by professionals from participating in decision - making regarding their children; and

e. Balancing time to attend to their other children, spouse, friends and to personal needs (Goel, 2002: 109).

\section{Social Inclusion}

Like most developing countries, is putting special emphasis on the achievement of the objectives of providing quality education, imparting relevant knowledge and developing proper attitudes, skills and habits among children and youth in order to ensure social inclusion (Ministry of Education, Science and Technology (MOEST), 2004: 16). Kenya's commitment to achieve the Education For All target, entails reaching out to the disadvantaged and vulnerable children and also to those in difficult circumstances, including girls, orphans, school drop outs, children with special needs, child workers, children of nomadic/pastoralist families, street children, refugees, mentally challenged, displaced children and destitute children. The Government of Kenya promotes the policy of partnership in addressing the educational needs of vulnerable groups. This enables the civil society, communities and the private sector to act as partners with the Government to initiate appropriate interventions for ensuring quality and appropriate education to the "hard to reach" groups. Together with education providers such as the community, religious institutions and Non - Governmental Organizations (NGOs), the Government is also supporting non - formal education institutions which admit mainly school drop outs, displaced and street children who may find it difficult to fit in the formal system due to its rigid nature. Although the Government of Kenya has implemented Free Primary Education (FPE), Mondoh et al. (2006: 1) observe that there are still serious problem with it. There are still a great number of children who enter the primary cycle but remain unable to complete it due to various reasons. This is an issue that preoccupies non - formal education providers in Kenya as well.

The Government of Kenya has also framed an appropriate legislation that ensures provision of education to all regardless of their circumstances. A key instrument in that respect is the Children's Act of 2001 that provides for education as a right to all children (MOEST, 2004: 18). In addition, the government is also acting as a signatory to the International Declarations and Protocols, which is a commitment for providing education to all the citizens so as to create a framework for enhancing social inclusion.

According to a survey conducted by the Ministry of Education, Science and Technology, the population of people with disabilities in Kenya is about 10 percent of the total population (MOEST, 2004:6). About 25 percent of these are children of school - going age. Out of this total of 750,000, an estimated number of 90,000 children we4re identified and assessed. Only 14,614 were found enrolled in different educational programmes for children with special needs; while an equivalent number of them were found integrated in regular schools. This implies that over 90 percent of children with special needs are either at home or in regular schools having a little or no specialized provision of assistance for them. Consequently, while the national literacy rate for the general population is about 75 percent, for the persons with special needs, it approximates 45 percent, (Oriedo, 2006). This may be due to lack of proper facilities and programmes for:

a. Mobilization and awareness development to eradicate taboos and beliefs associated with disabilities.

b. Development and implementation of a flexible curriculum that is child - centred in nature; and

c. Making the special education all - inclusive for children with special needs.

Although a number of Government documents have been produced on various issues related to children with special needs, there seems to be no clear - cut policy on special education to date. Nevertheless, there are a number of programmes and institutes oriented towards persons with special needs such as the Kenya Institute of Special Education (KISE), which provides training to special education teachers.

As a result of the World Conference on Special Needs Education held at Salamanca, Spain, in 1994, inclusive education is nowadays highly emphasized all over the world, including in Kenya. Inclusive education has mainly been interpreted to mean that all children with special needs be included in the traditional classroom. Abosi (2006) remarks that inclusive education is an advanced form of intergration 
which requires careful planning, provision of specialist teachers, individualized teaching, modified curriculum, possession of positive attitude to educating the children with special needs together with their peers. For inclusive education, it is not enough to merely provide academic inclusion. It is also essential to pay special attention to social inclusion so that these children may be recognized as equal and active members of the community and to enable them to face life with courage and confidence as well as to enjoy it.

However, achieving the target of social inclusion faces many challenges, including inadequate financial resources, differential culture, inappropriate curriculum, high cost of education, inappropriate policies set up for inclusion, inadequate teaching/learning materials, worn out and absolete equipment (MOEST, 2004: 16). There is also lack of determination on the part of the Government. As Oketch (2000) points out, pressure is required to change Kenya's Education system and to arm graduating teachers with some reasonable elements of special education. Teachers' role and that of the present special schools will have to be redefined. He further asserts that unless this is done rather urgently, the talk of inclusive education may remain a case of wishful thinking. Faulty attitude of family and community and differential behavior towards children with special needs may worsen the situation. Families of such children have urgent roles to play especially in enhancement of social inclusion for them. In this paper, an attempt has been made to analyze the various roles families can play in enhancing social inclusion of children with special needs.

\section{Parents}

Parents are the first educators of young children and parental involvement in early education programmes is a common denominator in school success (Nissani, 1993). After all parents appear to develop a sense of efficacy that communicates itself to their children, Okeke (2000) asserts that each individual usually belongs to a family system, so family is the most basic institution in our culture and the primary arena in which children learn to interact with each other and the environment. The family is also considered as the transmitter of biological and genetic endowments and a contributor to the psycho - social strength or vulnerability of its members. The family has a key role to play in the development of an individual. It is the family and especially parents who possess insight regarding the characteristics and needs of their children, which may be helpful in devising treatment and educational programmes according to the needs.

Barnett et al.. (2003: 184) argue that parental perception, thoughts and emotional reactions to their child's condition are the effective avenues for promoting adaptability. They define adaptation as an ongoing process whereby parents/family are able to sensitively read and respond to their child's signals in a manner conducive to healthy development. This is linked to social inclusion. Atkinson et al.. (1999) (qtd. In Barnett et al., 2003: 185) found that parental responsiveness and sensitivity are necessary for promotion of intimate attachment among children with special needs. Likewise, families make up the community and may initiate a change in attitude towards children with special needs. For example, most of the superstitious beliefs, values and customs which affect children with special needs are rooted in communities (Okeke, 2000). Communities are therefore required to change their attitudes towards such children.

Involvement of the family of the needy children as an active participant in any interaction programme is, therefore, crucial to the programme's success. Without it, any effort of intervention, at least in the cognitive sphere, erodes rapidly once the programme ends. Okeke (2000) suggests some measures to be followed in this regard, emphasizing that the successful education of children with special needs is dependent on the full involvement of their parents who should be seen and function as equal partners in the provision of education. The quality of family relationships and parenting behaviours, psychosocial resources such as perceived control, the ability to utilize social support and coping with stress have been identified as important features in helping family regarding health development as well as social inclusion of children with special needs (Barnett et al., 2003: 186).

\section{The Role of the Family}

Social inclusion should empower the family to be part of the team that plans for the child's future. Role performance of the family towards attainment of this goal is based on the assumptions that it:

a. Exerts the most powerful influence on the child;

b. Knows the child better than any other person, physiologically and psychologically.

c. Highlights the basic values and priorities in planning for any child's programme; and

d. Knows the strengths and weaknesses of the child well.

Against these assumptions, some important tips on role specification for the family of a child with special needs have been suggested in order to enhance their social inclusion:

i. To introduce the child to the community and others as early as possible. Thus, taking the child out into the community to open up a social environment for him/her.

ii. To allow the child to take up some risks for developing social relationships. This is a difficult process for anyone, with or without special needs. While balancing the risks, children are to be allowed to take the benefits that may accrue from such activities.

iii. To be willing and able to advocate for the social inclusion of the child, who is trying to learn how to ask for support in order to feel socially included.

iv. To get the child exposed to as many recreational and leisure pursuits as possible while making sure that he/she receives sufficient experience to engage in the types of recreation and leisure activities proffered by the peers in order to develop interests and preference in specific activities. 
v. To make sure that the child has ample opportunities to have similar experiences as the peers. To stimulate social relationships such as inviting the circle of friends of the child to jointly watch television programmes, listen to music, attend popular community and social events like birthday parties etc.

vi. To create a conducive atmosphere for making friendship as a family priority and scheduling time for the child to know and play with other children within the social neighbourhood.

vii. To find ways to assist and motivate the peers to interact with the child affectionately. Thus, parents of children need to be role model as they demonstrate cooperative play and effective communication with others so as to enable them to express their feelings properly (qtd. In Brown, 2002 - 2004).

Things the Family Should Not Do. The family should not:

a. Force the child on others and vice versa.

b. Over - protect the child; rather, the family should offer assistance that may promote independent work.

c. Motivate the child to be engaged in activities that are not socially valued by the peer group, i.e. be aware of the interests and dislikes of the child and those of similar age groups within the community.

d. Over - patronize the child as this may lead to dependency and lack of growth or even regression in behavior and skills.

e. Give - up, since failures are almost certain to occur; rather, it should accept unusual behaviours without allowing emotional outbursts that may have a negative impact on the child.

Support Sources for the Family:Barnett et al.. (2003: 190) and Heiman (n.d.: 13) suggest the following measures as sources of support for the family. They affect favourably the ability of a family to cope with and reduce the feelings of hardship and stress as well as contribute to successful functioning of social inclusion of children with special needs:

a. Cooperation, regular discussion, consultation with families and friends, as well as with professionals in strengthening family functioning.

b. Establishment of positive bonds between families especially those having children with special needs to support and strengthen each other;

c. Using various services available within the neighbourhood for diagnosis, treatment, counseling and training of children with special needs as well as for assisting family members to take proper care of such children; and

d. Establishment of positive parent/family - child attachment for promotion of social and emotional relationships and well - being of children with special needs.

\section{Conclusions}

A child with special needs may create stress, confusion and anger in most families regardless of the precise nature of the special needs (Heiman, n.d.: 14). However, this should not frustrate the family; rather, it should encourage them further to adapt to the changing needs of the child with special needs. Parents may introduce their children with special needs to the community to get them exposed to various life situations and also to provide valuable and varied nature of experiences to enhance social inclusion through the process of socialization. Making available the required services and education to such children is the main responsibility of the family, and to meet this end, the family requires proper education and training to cope with the needs of such children and seek assistance from the Governmental. Both academic and social inclusion should be secured through the process of education while avoiding over - patronizing and over - protection of children. Families should never give up hope and never relinguish their efforts to be firmly in touch with their children, following their likes and dislikes. The Government should initiate measures to educate families to cope with the situation they are in. all stakeholders should strive to provide models of education on social inclusion for children with special needs while avoiding any sort of exclusion, i.e. academic, physical or psycho - social.

\section{REFERENCES}

[1] Abosi, C.O. (2006) "Thought on an Action Plan for the Development of Inclusive Education in Africa". Last modified on February 7, retrieved on April 20, 2006 from http://www. Ideapractices.org/intl/natlover.html

[2] Alur, M. (2002) “Introduction”. In: S. Hegarty \& M. Alur (eds) Education and Children with Special Needs: From Segregation to Inclusion. New Delhi: Stage Publications India Pvt. Ltd., pp. $15-38$

[3] Barnett, D., M. Clements, M. K. Estrin \& J. Fialka (2003) "Building New Dreams: Supporting Parents' Adaptation to Their Child with Special Needs". Retrieved on April 20, 2006 from

http:/specialkidstoday.com/resources/articles/likeme2.htm

[4] Goel, S.K. (2002) "Inclusive Education, Family Support Services and Information Networking." - Journal of Indian Education, Vol. XXVII, No. 4, pp. $100-115$

[5] Heiman, T. (n.d.) "Children with Special Needs: The Role of the Family". Retrieved on March 23, 2006 from www.open.ac.il/geninfor/openletter/12-14.pdf

[6] Julka, A. (2002) "Development of Inclusive Education in the SAARC Countries: A Regional Perspective". - Journal of Indian Education, Vol. XXVII, No. 4, pp. 43 - 53

[7] Malhotra, R. (2002) "School Reform Strategies for Inclusion" - Journal of Indian Education, Vol. XXVII, No. 4, pp. 21 - 31

[8] MOEST (2004) :Development of Education in Kenya: Ministry of Education, Science and Technology." Retrieved on March 23,2006 from www/ ibe. unesco.org /international /ICE47/English/Natreps/reports/Kenya,pdf

[9] Mohay, H. \& D. Woodhouse (2002) "Barriers and Solutions to Inclusive of Children with Disabilities in Child Care". - 
Journal of Indian Education, Vol. XXVII, No. 4, pp. 1 - 15

[10] Mondoh, H.O., N.O. Omar, J.M. Changeiywo \& J.M. Wamutitu (2006) "Managing the Process of Growing - up and Sexual Maturation: Information Needs of Kenyan Primary School Children". - National Journal of Education, Vol X, No. 1, PP. 1-6

[11] Nissani, H. (1993) "Early Childhood Programs for Language Minority Students". Online Resources: Digests, Northwest Regional Educational Laboratory, Retrieved on September 29,2007 from

http://www.isec2000.org.uk/abstracts/papers_o/okeke_1.htm
[12] Oketch, M.T. (2000) "Changing Roles: The Case of Kenya." Abstract of a Paper Presented at the International Special Education Congress (ISEC) 2000, held at the University of Manchester, July 24 - 28, 2000, Retrieved on March 5,2006 from

http://www.isec2000.org.uk/abstracts/papers_o/okeke_1.htm

[13] Oriedo, T. (2006) "The State of Persons with Disabilities in Kenya." Last modified on February 7, retrieved on April 20,2006 from http:// www.ideapractices.org /intl/ natlover.html 